\title{
Evaluation of the results of ulnar lengthening for correction of forearm deformities in multiple exostoses (Diaphyseal aclasis)
}

Keywords: diaphyseal aclasis, ulnar shortening, ulnar osteotomy, radial head dislocation, ilizarov

\section{Introduction}

This disorder is an autosomal dominant inheritance. Long bones are more severely affected than the ribs, spine, scapula and pelvis. Most frequent in metaphysis of proximal and distal femur, proximal and distal tibia, distal radius and ulna. Ulna is shorter than the radius; radius is bowed laterally with its concave to the short ulna. Progressive posterolateral dislocation of the radial head is a common deformity. At wrist radial deviation is restricted and ulnar deviation is increased. Multiple hereditary exostoses (MHE) produce characteristic deformities of the forearm leading to problems at the wrist and elbow. Understanding the patho-anatomy allows one to correct all these deformities in a single or staged fashion. The purpose of this study is to report our clinical experience in the treatment of evaluation of the results of ulnar lengthening for correction of forearm deformities in multiple exostosis. We have corrected skeletally immature patients as well as adult patients to illustrate the scope of deformity and treatment. ${ }^{1-6}$

\section{X-ray findings}

Metaphyseal area is broadened. Deformity is trumped shaped.

\section{Classification:}

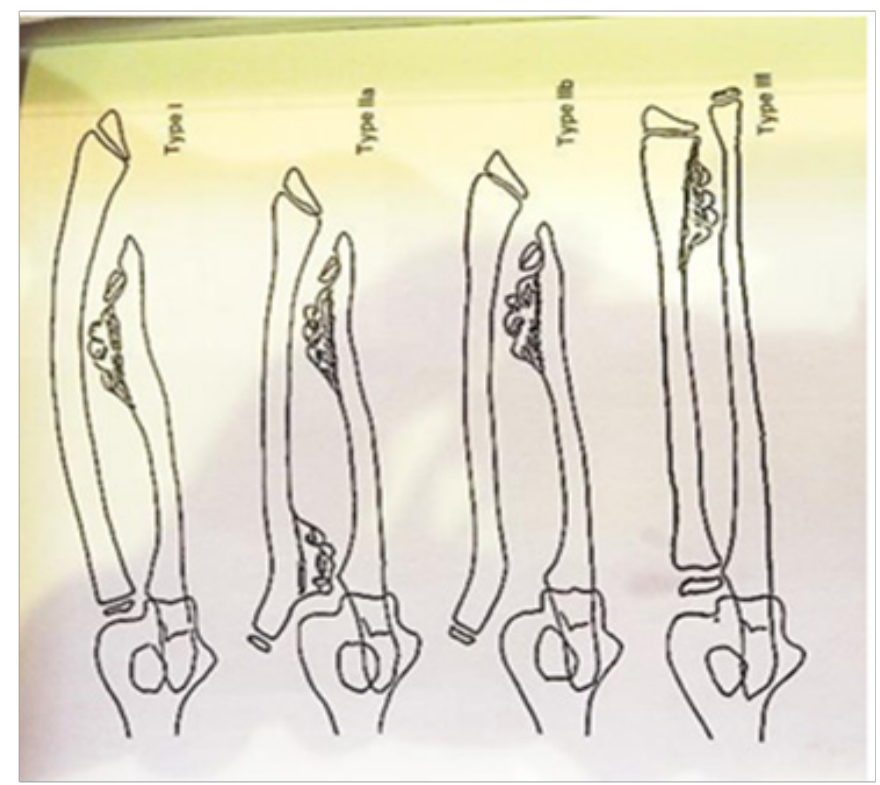

We follow the classification of Masada and Ono in MHE.

Type I: Ulna is short, osteochondroma formation at the distal ulna.

\author{
Volume 10 Issue 5 - 2018
}

\begin{abstract}
Bari MM,' Shahidul Islam, ${ }^{2}$ Mahfuzer Rahman ${ }^{3}$ 'Chief Consultant Bari-llizarov Orthopaedic Centre,Visiting and Honored Professor of Russian llizarov Scientific Centre, Kurgan ${ }^{2}$ Professor Bari-llizarov Orthopaedic centre, Bangladesh ${ }^{3}$ Consultant Bari-llizarov Orthopaedic centre, Bangladesh
\end{abstract}

Correspondence: Bari MM, Chief Consultant Bari-llizarov Orthopaedic Centre,Visiting and Honored Professor of Russian llizarov Scientific Centre, Kurgan, Bangladesh, Email bari.ilizarov3।@gmail.com

Received: September 30, 2018 | Published: October 02, 2018

Type IIA: Ulna is short, osteochondroma formation at both proximal radius and distal ulna, radial head dislocated.

Type IIB: Ulna is short, osteochondroma formation at the distal ulna, radial head dislocated.

Type III: Radius is relatively short to the ulna, osteochondroma formation at the distal radius

\section{Patients and method}

This is a retrospective review of 12 patients between 2000 and 2017 in NITOR and

Bari-Ilizarov Orthopaedic Centre. The pre and post-operative radiographs were evaluated.

\section{Treatment}

\section{Indications}

1. If it interferes with muscle function

2. Causes pressure symptom on nerve and vessels

3. Visible deformity

MHE is an incurable condition. An individualized treatment is planned and provided to improve the quality of life, based on the specific condition, and complications that are present $t^{1,2,5}$

\section{Procedure}

1. Debulking of the distal ulnar exostosis if it causes pain or significant restriction of forearm motion. This is not always needed.

2. Fixation across the distal radioulnar joint with one smooth tensioned wire.

3. Distal distraction of radius to achieve closed reduction of the radiocapitellar joint dislocation. 
4. Overcorrection of the radiocapitellar joint to compensate for the radius plus deformity at the wrist.

5. Proximal migration of radius after the removal of the Ilizarov frame to achieve normal radiocapitellar joint and distal radioulnar relationship.

6. Over lengthening of the ulna can be considered in younger children where future growth discrepancy is anticipated.

7. Distal growth plate and epiphysis are carefully preserved.

8. Lengthening of the ulna is done by Ilizarov technique till it reaches the distal radius.

9. The bowed radius is corrected if there is a dislocation of the radial head, this can be corrected by Ilizarov method. Osteotomy is done in the proximal ulna to lengthen the bone, the radial head is brought down to the olecranon. Sometimes it is needed to do Bell-Tawsy operation (pathological condition at radiohumeral joint, use of fascial strip from triceps tendon). ${ }^{5,6}$

\section{Results}
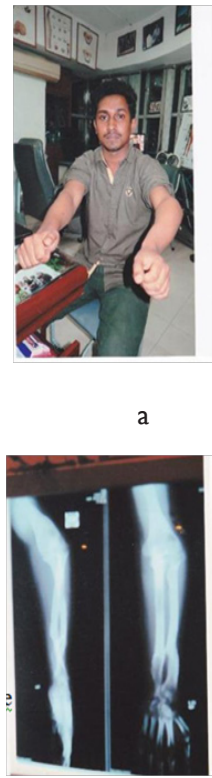

e

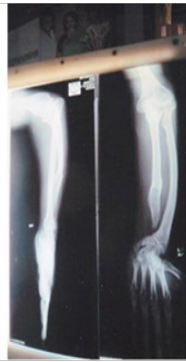

b

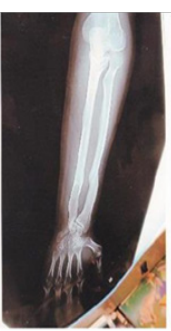

c

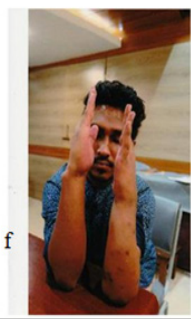

\section{Case study I}

a. Clinical picture $-23 y$ rs. Old man showing a marked forearm elbow deformity due to subluxation with proximal migration of lt. radial head

b. Radiograph showing the short ulna with radial head subluxation

c. Radiograph with Ilizarov in situ

d. Patient with Ilizarov in the left forearm

e. After full correction of the radial head deformity and ulnar shortening

f. Clinical appearance of the patient after 1year

\section{Case study II}

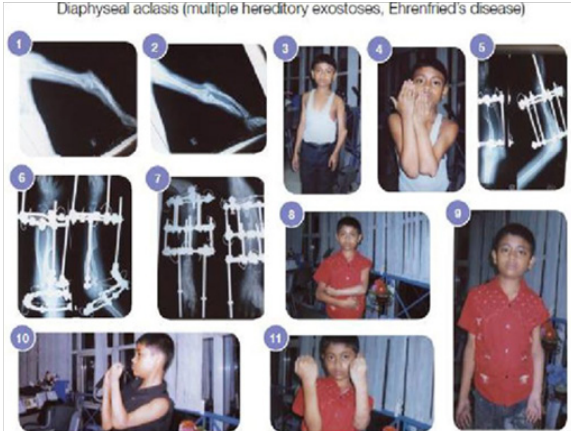

1.2. Left radial head is migrated, uha is shortened

3.4. Clinical photograph of 14 years old boy before

Process of distraction of radial head

6. Racilial head is at the level of capitelum.

7. Radograph of proximal corticotormy of una and distraction is seen, distal rado unar jont is maintained. 8.9.10.11 Cirical appearance of the petient efter 5 months follow up.

\section{Discussion}

Hereditary Multiple Exostosis (HME) is a familial condition that causes the development of numerous bone tumors at various locations in the body, the bone in the body may be affected by HME. These bony tumors are called 'exostosis'. Most individuals start developing these benign tumors when they reach the age of 12 years. These tumors usually occur during the growth phase of one's life. As one becomes an adult, the growth of new tumors does not occur. It is estimated that around or less than $5 \%$ of the individuals with HME develop malignancy. Uneven limbs, bone abnormalities and associated defects and joint movement restrictions are the signs and symptoms of HME. Defects and deformity can be fantastically corrected by Ilizarov technique. Most individuals with mild hereditary multiple exostoses can lead relatively normal lives. However, the prognosis depends upon the number of bone tumors, its locations, and where the benign tumors have turned malignant. ${ }^{4-7}$

\section{Conclusion}

As with any deformity correction adequate preoperative planning and analysis are imperative. We shall have to plan staged surgeries-for example to reduce the radial head after gradual transportation of the radius. Correction of forearm by corrective radial osteotomy and ulnar lengthening by distraction osteogenesis through Ilizarov technique is an unique method for MHE OR HMEs. ${ }^{5,6}$

\section{Acknowledgements}

None.

\section{Conflict of interest}

The author declares no conflict of interest.

\section{References}

1. Ehrenfried A. Multiple cartilaginous exostoses-hereditary deforming chondrodysplasia- a brief report on a little known disease. JAMA. $1915 ; 64: 1642$.

2. Ehrenfried A. Hereditary deforming chondrodysplasia- multiple cartilaginous exostoses-A review of the American literature and report of 12 cases. JAMA. 1917;68:502. 
3. Bari M. A color Atlas of Limb Lengthening Surgical Reconstruction and Deformity Correction by ILIZAROV TECHNIQUE. 2013:304-305.

4. Svetlana Ilizarov S, Robert Rozbruch. Limb lengthening and Reconstruction Surgery. USA: Informa Healthcare, Inc. 2007:555-566.

5. Robert Rozbruch S, Reggie C Hamdy. Limb Lengthening and Reconstruction Surgery Case Atlas. Switzerland: Springer International publishing; 2015:637-666.
6. Yong JC, Jung ST. Gradual lengthening of the ulna in patients with multiple hereditary exostoses with a dislocated Radial head. Yonsei Med J. 2014;55(1):178-184.

7. Bari M. Ilizarov Compression Distraction method in Paediatric Orthopaedics. First ed. 2016:138-141. 